\title{
What is it to do good medical ethics? A kaleidoscope of views
}

\author{
Raanan Gillon, ${ }^{1}$ Roger Higgs ${ }^{2}$
}

This special issue of the journal is a birthday issue. A fortieth birthday is usually the time for more than pure celebration: a rueful glance in the mirror at the beginning to check on grey hairs, taking stock about whether achievements come anywhere near those carefully laid plans, cautious conversations with people who've been around that long too (with a wary look at the younger ones who might have been expecting a lot more); and then a long, deep breath about what comes next.

This anniversary is no different: 1975 was indeed a special year. Many will want to know what happened then and since, and why: Alastair Campbell, as the founding editor (and writer of one of the first modern books published on clinical ethics in the UK) describes it clearly, and Gordon Stirrat's focus on teaching and Roger Higgs's on case discussion add further dimensions. But equally important questions for this birthday issue need to be posed about what medical ethics in general, and the Journal of Medical Ethics in particular, have achieved, and what they haven't; and where they should be going from here.

It was the present editor-in-chief Julian Savulescu who suggested that these questions might be addressed by making the theme of JME40 the open-ended question 'What is it to do good medical ethics?' We snapped up this idea. But who should we invite to answer the question? We started by asking the JME's editors past and present, and then we added our own choices. There were far too many, even for the bumper size of this special issue, and we remain desperately aware that many we should have liked to have asked have not been included. But as Kirkegaard said, to start sewing you have to knot the end of the thread, and we hope and assume that other writers will forgive the guest editors by engaging with the question and responding to the challenge of

${ }^{1}$ Imperial College London, Department of Primary Care and Public Health, London, UK; ${ }^{2}$ Emeritus Professor of General Practice, King's College, London, UK.

Correspondence to Raanan Gillon, Emeritus Professor of Medical Ethics Department of Primary Care and Public Health, Imperial College London, Charing Cross Campus, London W6 8RP, UK or 42 Brynmaer Road, London, SW11 4EW, UK;

raanan.gillon@imperial.ac.uk answers offered in this collection to give the topic the thorough airing it deserves.

As its title makes clear the JME is primarily (though not exclusively) concerned with ethics in medicine, and we have continued that emphasis in this issue. The breadth of concern that this nonetheless permits will be evident, and Sarah Chan's reflections on bioethics include an interesting account of the distinction. Thus while clinicians with a developed interest in medical ethics are represented (some also medical school teachers, members of medical ethics think tanks, legislators, or administrators), so too are patients and managers, as well of course as a wide and international range of professional bioethicists with a background in philosophy. We sought input too from sibling concerns including medical law, medical economics and medical humanities. We also explicitly asked three clinician-ethicists to consider 'good medical ethics' from their specific Christian, Islamic and Jewish religious perspectives. Conscious of the danger of too narrow a focus on the doctor-patient interchange, we asked for contributions from the perspectives of public health and global justice: and we have responses to our 'set question' from Argentina Australia Denmark Egypt Holland Israel Norway and Singapore as well as from the UK and the USA. There is no shortage of criticism even amongst our older writers (including ourselves) who look back, explain origins, compare past and present; but as we would expect younger contributors tend to focus more on the present and future states of medical ethics.

\section{SOME EMERGENT THEMES}

Unsurprisingly, many authors addressed the issue of what 'good' in our question might mean. The most extensive of these analyses is by Jan Solbakk and his ideas resonate throughout this issue. No birthday could be complete without celebration, and in view of its contribution to the growth and development of medical ethics and bioethics over the last 40 years this journal does receive some plaudits for having 'done good', in Art Caplan's phraseology. We were especially pleased to read the praise of Julia Neuberger, a previous Chair of the Patients' Association, and a tireless campaigner on behalf of all who use health services. By its support over the years for 'the increasing focus of medical ethics on the interests and perspectives of the patients/clients/consumers/service users whose interests doctors and other health care workers serve' the $J M E$, she writes, 'has itself made a significant contribution to "doing good medical ethics"'.

However as she and most contributors make clear in this issue the glass of medical ethics is nowhere near full. Optimists and pessimists exist in all walks of life, and while some contributors see it as half full others emphasise that the glass is certainly half empty, and maybe considerably emptier than that, as in Julian Savulescu's very challenging assessment. The warnings are there, in many places. Brian Hurwitz searches in the attic and reflects on the significance for medical ethics of medical and nursing mass murderers. Paquita de Zulueta warns that without a major change of emphasis towards an ethics of virtue and a concern for compassion and human dignity 'medical ethics risks becoming another method for creating alienation, moral disengagement and the reification of humanity, with all the dangers that this entails'. Justin Oakley too recommends a virtue ethics approach, arguing that it requires both 'an empirically based moral psychology' and 'sound action guiding prescriptions' if the virtues of physicians are to be developed. Dan Callahan warns of danger from without as well as within: good medical ethics must tackle 'a progressand technology-driven model of medicine that is its basic or core value' It is a drive, he writes, 'that knows no limits' and which is unsustainable. Medical ethics has failed 'to say that every technological innovation should have to pass a test of whether it will be good for humans'.

Rosamond Rhodes offers one explanation of why a glass half empty perspective is needed when considering good medical ethics. Appealing to a metaphor of the philosopher J.L.Austin she writes: 'to be more informative about what good medical ethics is, requires explaining what bad medical ethics is. In this case, bad medical ethics wears the trousers'. There is no question that there is plenty of material to work on. While all contributors welcome the opening up of medical ethics debate and the increase in moral education in clinician's training over the last forty years, this alas is not a magic that will chase away all bad actions and tragedies caused by human inadequacy. Scandals epitomised by the appalling patient care in UK National Health 
Service hospitals in mid Staffordshire and described in the Francis Report cast doubt on the usefulness of medical ethics discussion and education. As Wing May Kong puts it: 'If we look into the mirror post-Francis, surely those of us who champion the importance of medical ethics must admit that currently medical ethics is not good enough?' To help remedy this she proposes three priorities: the building up of an ever larger 'ethics community' across health care-currently medical ethics is too much of 'a minority language'; the necessity in teaching and implementing good medical ethics of 'nurturing our moral imagination'; and 'resisting tick-box ethics'.

But the contributors to JME40 show that medical ethics can be 'not yet good enough' in many other ways. Several of the professional philosophers point to what they consider to be poor reasoning, whether from ethicists or doctors. Savulescu leads the charge with a critique of the poor thinking of rote moralism, in which words and concepts sometimes make no sense-his example, coercing an embryo- or which fails properly to confront its arguments with counterarguments. Emphasising the duty to prevent avoidable deaths he argues that the requirement for consent to share records for medical research or for transplantation of organs from dead bodies should give way to the clear moral obligation of 'easy rescue'. Nearer to the patient, Kenneth Boyd sees a similar problem in his thorough examination of informed consent, while Rhodes argues that medical ethics can go wrong too by failing to be illuminating in cases of moral dilemmas, by being inaccurate, unreasonable, too simple, inconsistent, and not measured. As she somewhat ruefully concludes 'Long ago, Aristotle remarked that when you try to do the right thing, it is hard to hit that target. That's because there are so many ways to go wrong.' Dan Brock also homes in on poor reasoning. 'Training in careful, rigorous argument, whether from philosophy or elsewhere is necessary for good bioethics and unfortunately too much bioethics displays both its importance and its absence'.

Giving examples of poor argument in medical ethics Ruth Macklin emphasises that 'Yuck is a conversation stopper not an argument.' While few would disagree about the need for good reasoning in medical ethics, turning it into action remains a problem. One aspect of this concerns the moral responsibility to warn that something bad is or may be happening, whether within one's own institution (hard but brave) or elsewhere (maybe easier but a lot less brave), and then to respond with appropriate action. Higgs nonetheless reminds us that the strong feeling that something is just not right here, even if we haven't yet got the words for it, may be a warning that good ethical thinking and action may be necessary. $\mathrm{He}$ re-describes a published case from the $J M E$ where a relative's anger led to a hightension teaching session for medical students and resolution of a substantive problem. Rhodes on the other hand gives an example of an elderly physician wrongly accused and so diminished both reputationally and practically by having to run the gauntlet of ethics colleagues' adverse opinions. While we may have to conclude that if the jury is never asked to sit, bad things may continue to happen, those who make accusations have the responsibility to measure their words, make sure the process is as good as it can be and, as well as they can, take care of the consequences.

\section{BIOETHICS, MEDICAL ETHICS AND 'THE MULTIPLE HAT PROBLEM'}

While no contributor to JME40 has argued that careful rigorous argument is not 'necessary for good bioethics' not all contributors, or readers, will agree with Brock's suggestion (based on his arguments in other papers) that defence of the possibility of moral distinctions between killing and letting die must be based on poor argument.

In a perhaps related point Stirrat states that 'non-medical bioethicists sometimes fail to grasp clinical realities'; and he adds that sometimes their reasoning and argumentation skills may actually make clinicians 'feel inadequate, making them apprehensive about getting involved in formal ethics teaching'.

In a thorough review of arguments rehearsed in the JME since its beginnings concerning euthanasia and physician assisted suicide Soren Holm, a past editor, concludes, amongst other things, that writers on this subject are often not careful enough to distinguish between and be honest about their twin objectives of rigorous argument and political activism - a point also made by Solbakk. This is an aspect of what Chan calls 'the multiple hat problem' in bioethics and of deciding and making clear 'which hat we are wearing at any given time. Who are we talking to and for what purpose?'And she adds: 'Doing bioethics requires an awareness of the multiple roles that bioethics is called upon to play, and knowing how to balance them is a part of good bioethics'.
This theme is also pursued by Bobbie Farsides in reflecting on her work as an ethicist in a medical school where her hats include those of teacher, philosopher, social scientist and active participant in the surrounding community. Her summary perception of doing good medical ethics is that it is 'practical in approach, philosophically well grounded, cross disciplinary'; and, she suggests, often done by good people.

\section{TOLERANCE AND CONSCIENTIOUS OBJECTION}

While rigorous reasoning is agreed to be necessary to do good medical ethics, few if any contributors would find it to be sufficient. The role of religion in their approaches to doing good medical ethics is discussed, in three fascinating and very different accounts, by John Saunders, Gamal Serour and Avraham Steinberg. Each considers the importance and limits of tolerance for conscientious objection and each discusses in this context the issue of abortion. Florenzia Luna also addresses the theme of conscientious objection to abortion and proposes an ethical response to conscientious objection in the 'non-ideal circumstances' (one of Solbakk's varieties of goodness) of what she regards as Argentina's failures to uphold its own already restrictive law on abortion.

Several contributors emphasise the need to incorporate a variety of psychological factors when 'doing good medical ethics' including a concern to increase the use of imagination and compassion and to value people's emotional responses more highly. While Higgs sees moral thinking often arising from response to difficulties in the emotional sphere, de Zulueta argues that 'proficiency at moral reasoning, although important, does not necessarily translate into ethical behaviour', and writes that the emotional dimension may be missing in much of the discourse and teaching of medical ethics. 'In this context, emotions are often viewed as a hindrance, rather than an aid, to making sound decisions. The revival of virtue theory, which incorporates emotions within rational ethical decisionmaking, the inclusion of philosophical emotion theory and neuro-scientific knowledge in clinical ethics are thankfully reversing this trend'.

In her characteristically quirky and amusing contribution Inez de Beaufort recommends to bioethicists, among many many other suggestions, that 'one should be personally involved in the issues one thinks and writes about and [try] to bridge the gap of "moral distance". 


\section{THE DEMOCRACY OF MEDICAL ETHICS}

Even if only from a 'glass half full' viewpoint, most contributors would probably agree that a positive development in medical ethics over the last forty years has been the recognition that many different perspectives are needed for 'good medical ethics'. They are likely to agree with Solbakk's claim that 'ethics represents a domain and a form of knowledge different from any expert knowledge, in the sense that everybody-and notably on equal terms-is entitled to partake in public debates, dialogues and deliberations about moral issues that might affect his or her life'. Savulescu's concerns about lack of training of so called experts in medical ethics notwithstanding, Neuberger, Callahan, Caplan and Bowman all write about the importance of involving the public, and all four, like many others in this issue, are prolific contributors in the non-academic media. De Beaufort, on being told by her (academic) publisher about 200 downloads of one of her academic articles asks herself whether it would have been better in the time it took her to prepare that paper to 'have written 5 contributions for the popular press?'. A shining example of interdisciplinarity in medical ethics and of the glass half full approach is Mike Parker's account of the 'genethics club' and his emphasis that 'the moral craftsmanship' of doing good medical ethics is a cooperative rather than a competitive activity.

\section{INDIVIDUALS AND POPULATIONS}

One of the recurring tensions in this collection of papers is between good medical ethics that is concerned primarily with how doctors should interact with their patients and good medical ethics that expands the proper concerns of medical ethics to ever larger 'spheres of justice'. Angus Dawson vigorously reminds doctors that good medical ethics is typically too orientated to individuals, arguing that it should instead incorporate far more concern for communities, as in public health ethics. Writing as the epidemic in west Africa was beginning to threaten to spiral out of control, he cites a WHO response to the Ebola crisis as demonstrating the faults of traditional individual-orientated medical ethics. Richard Cookson points out, as a good health economist should, that good medical ethics requires 'consideration not only of the identified patients who benefit from decisions, but also the unidentified patients who bear the opportunity costs'.
In a similar vein Savulescu argues that preventing avoidable loss of life is a fundamental obligation of good medical ethics.

'There is a moral imperative to perform good research and not unnecessarily impede it. To delay by one year the development of a treatment that cures a lethal disease that kills 100000 people per year is to be responsible for the deaths of those 100000 people, even if you never see them'.

The JME started publishing a full 30 years after the end of World War Two, but several others of our contributors are far from happy about how the consequences of the new ethical oversight of medical research that followed that war have worked out. Like Savulescu, Solbakk writes about the 'dysfunctionality' of sometimes 'exploitative' international medical research ethics'. They both question the Helsinki Declaration's 'normative bedrock of clinical research' - namely that the interests and welfare of the individual should have priority over the sole interest of science or society. Solbakk urges 'concerned ethicists to join forces' and move away 'from the microlevel of informed consent and of quasi-consensual transaction procedures to a level of deliberation that grounds international medical research ethics 'within a broader normative framework of social, distributive, and rectificatory justice'. More broadly still, Jennifer Prah Ruger argues that too little account is taken by medical ethics, bioethics and political philosophy of 'the capability to flourish' as being 'the proper goal of social and political activity'. Crucially underpinning this goal are 'health capabilities and specifically central health capabilities-freedom from avoidable morbidity and premature death', for these are essential for human functioning and thus underlie all other capabilities. Prah Ruger offers components of a global health justice framework based on this health capabilities approach that she calls 'provincial globalism'. (Smug Brits may also be struck by her claim that a free national health service was provided over 3000 years ago by the ancient Egyptians!).

A different aspect of justice-legal justice- in relation to medical ethics is discussed by Emily Jackson, who teases out some of the puzzling and sometimes confusing relationships between medical ethics and law. That this directly affects publishers of medical ethics is discussed by Higgs, who thinks that legal restrictions including the UK's strict libel laws and data protection laws run the risk of making case discussion in print about conflict situations well-nigh impossible, however well details are anonymised.
Several of the papers in this issue, including those by John Harris (another past editor) Kong and De Beaufort, discuss yet another aspect of 'doing good medical ethics', the importance of teaching and mentoring students and younger colleagues both in the medical context and within academic medical ethics and bioethics. Harris suggests several modelsincluding a research lab model and a 'renaissance studio' model in which this teaching and mentoring might occur and help the 'research-craft' of younger colleagues to 'dock safely at the big quay of academia'.

\section{'PRINCIPLISM' AND MEDICAL ETHICS}

An important tension emerges in this collection about the role of 'principlism' or 'the four principles approach' in relation to good medical ethics. Supporting their use are Macklin who concludes that 'the "famous four" principles provide the best approach', Raanan Gillon, another past editor, who argues that 'they are a good moral framework' that underpins a contemporary 'moral mission statement' for good medical practice and thus for good medical ethics, and Ilora Finlay who finds them a helpful moral framework both in her clinical work and in her legislative work in the United Kingdom's House of Lords where 'the core principles of the classical framework outlined by Beauchamp and Childress can be seen to come into play'. On the other side however are several contributors with Rhodes in the lead castigating principlism for being 'incoherent' (by which it is clear that she means that they do not cohere with good medical practice) and 'not illuminating' (because 'the four principles do not provide a mechanism for resolving dilemmas'). She joins Kong in criticizing the approach for encouraging 'tick box ethics' and writes 'A formulaic approach that requires rote-wise ticking off principles or topics can be inefficient and distracting without clarifying the issue or helping to resolve the problem'. De Zulueta also implicitly lays into principlism, arguing passionately for the necessity of a virtue-based approach. A virtue ethics approach that Gillon argues seems to be compatible with principlism is provided by Oakley, who stresses the importance of good empirical studies both for determining which aspects of 'the internal morality of medicine' actually serve the 'central goal of medicine' of 'serving patient health'; and which professional and political norms and requirements actually promote that internal morality. In the context of the principles several writers 
complain about over-emphasis of respect for autonomy though both Callahan and Boyd, in his excellent discussion of informed consent, detect movement in contemporary medical ethics towards what the latter describes as 'a possible rebalancing' of beneficence over respect for autonomy when these conflict.

Perhaps a final glass half full perspective is expressed by Caplan who summarizes a general agreement by contributors to JME40: that while there are many ways to do good bioethics and good medical ethics 'One crucial way is to do good'.

This issue of the JME certainly doesn't provide a canonical account of what it is to do good medical ethics: on the contrary it provides a wide range of different accounts in which are proposed many different ways in which medical ethics should be improved. Kenneth Calman proposes setting up a multidisciplinary committee or commission, national or perhaps international, which should include the perspectives of patient groups, to continue to look at the question and 'enlighten the professions, the patients and the politicians'-a view succintly endorsed by Bowman in recommending 'actively seeking perspectives and contributions from people other than academics and clinicians'. Such a committee could do worse than start with the kaleidoscope of views presented in this volume-and referred to in the treasure house of their authors' references.

Finally we must thank those who let us guest edit this 40th birthday issue in the first place:above all Julian Savulescu, who, when Roger originally suggested the idea of a special $40^{\text {th }}$ anniversary issue at a meeting of the IME Governing Body, so readily accepted its proposal and allowed the two of us to be its guest editors. Julian has played a hands-off Editor-in-Chief's role throughout, and we should emphasise that any brickbats must come our way! With him we should thank the IME/BMJ joint journal management committee for so generously (and we hope farsightedly) agreeing to the plans and to our request for a double issue for JME40.

We also thank all the 'backroom' staff who, as always, play such a vital role in production of the JME. Amongst them we particularly thank Miriam Wood, administrator extraordinary, Bernadette Berido, who has been tireless in support of us and contributors, production editor Emma Chan and journals manager Claire Weinberg for all dealing so effectively with the many problems as they arose, and without complaint (at least to us!). More broadly we thank all the people who have helped produce the JME over the last 40 years. It would be impossible to name them all and invidious either to try and fail or else to select just a few. Suffice it to doff a hat to the founder, the various editors, their many assistants, the board members, the unsung army of peer reviewers, the publishing staff, and above all the thousands of writers. Between them all they have built up the JME to become a splendid example itself of good medical ethics, recently ranked by Google Scholar as the top bioethics journal, and by ISI as no 2 on the basis of academic journal impact factor alone. Happy fortieth birthday, JME.

So 'what is it to do good medical ethics?' Please read on.

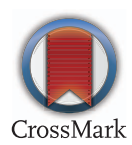

To cite Gillon R, Higgs R. J Med Ethics 2015;41:1-4. J Med Ethics 2015;41:1-4. doi:10.1136/medethics-2014-102571

A limited number of single copies of this $40^{\text {th }}$ anniversary issue of the Journal of Medical Ethics will be available to purchase from the Institute of Medical Ethics via the following url: http://ime. datawareonline.co.uk/Events 